\title{
A Quantitative Exploration of Continuous Vaccination of the COVID-19 Vaccine: an Empirical Study From China
}

\section{Wenlong Zhu}

Qingdao University of Technology

Hao Zou

Qingdao Medical College: Qingdao University Medical College

Ying Song

Qingdao University of Technology

Yingjie Xu ( $\nabla$ xyjdywe@163.com )

Qingdao Stomatological Hospital

\section{Research}

Keywords: Novel coronavirus disease 2019 (COVID-19), continuous vaccination, Health Action Process Approach (HAPA) Model, Expectation Confirmation Model (ECM), vaccine hesitancy (VH) theory

Posted Date: September 7th, 2021

DOI: https://doi.org/10.21203/rs.3.rs-861159/v1

License: (c) (i) This work is licensed under a Creative Commons Attribution 4.0 International License. Read Full License 


\section{Abstract}

Background: Vaccination for the novel coronavirus disease 2019 (COVID-19) provides an effective approach for the general improvement of social safety and individual health. However, to date, few studies have analyzed the continuous vaccination for COVID-19 vaccine and its impact process. This research explores factors that theoretically affect the public's continuous vaccination for COVID-19 vaccine at every stage and constructs a theoretical model to analyze the entire impact process of continuous vaccination based on the Health Action Process Approach (HAPA) Model, the Expectation Confirmation Model (ECM) and the vaccine hesitancy (VH) theory.

Methods: The respondents in this study were individuals in China who have been vaccinated. In addition, structural equation modeling technology was used to analyze the influence of factors on the continuous vaccination for COVID-19 vaccine and the whole impact process.

Results: First, perceived efficacy has a positive significant impact on vaccination intention, but the positive effects of outcome expectancy and risk perception on vaccination intention are not significant. Second, social positive cues have a positive significant influence on vaccination intention. Third, VH has a negative significant influence on vaccination intention. Four, vaccination behavior produces a positive significant effect on perceived usefulness and satisfaction, respectively. Five, perceived usefulness exerted a positive significant impact on satisfaction and continuous vaccination, respectively. Six, satisfaction has no positive significant influence on continuous vaccination.

Conclusions: Our theoretical model, which is the main contribution of this research, indicates that individual continuous vaccination is a process from motivation to intention, and from intention to behavior, and then from behavior to continuous behavior.

\section{Introduction}

At the end of 2019, the novel coronavirus disease 2019 (COVID-19) broke out in the form of a pandemic, and the rapid onset of this disease has brought with it considerable challenges for many or all countries in the world (including challenges in political, economic, social, and security sectors) [1]. Today, more and more countries are developing COVID-19 vaccines to prevent the epidemic [2]. For example, the United States of America started vaccinations on December 15, 2020, and as of July 4, 2021, the U.S. had successfully administered 330.60 million doses [3]. By the end of 2020, the 27 countries of the European Union had begun vaccinations. By July 7, 2021, more than 380 million citizens across the European Union had received the COVID-19 vaccine [3]. China began implementing COVID-19 vaccinations at the end of 2020 , so that by July 7,2021 , the number of vaccinations had exceeded 1.32 billion doses in that country [3]. Currently, governments around the world still believe that the COVID-19 vaccine will prove an effective means of preventing the epidemic.

Although various countries are actively carrying out COVID-19 vaccinations, it is undeniable that the COVID-19 vaccines developed at this stage usually have an expiration date (maybe the expiration date of 
the COVID-19 vaccine developed in each country is different, but all vaccines have an expiration date due to limited time for development). In other words, COVID-19 vaccines will expire after a period of time and will no longer protect the public who have been vaccinated. At this time, if countries around the world still cannot identify a better approach to preventing the virus, people will have to vaccinate again in order to protect themselves. Therefore, governments around the world will face the following critical question:

RQ: what factors will affect the continuous vaccination of COVID-19 vaccine?

In response to this issue, we intend to explore the key factors of citizens' continuous vaccination and analyze the process and effect of these factors on continuous vaccination. At present, there are relatively few academic studies on continuous vaccination for COVID-19. In light of this, the present study explores factors that theoretically affect the public's continuous vaccination at every stage and constructs a theoretical model to analyze the entire impact process of continuous vaccination based on the Health Action Process Approach (HAPA) Model, the Expectation Confirmation Model (ECM) and the vaccine hesitancy $(\mathrm{VH})$ theory. Then, we empirically evaluate the direct and indirect effects of factors at every stage of the continuous vaccination process.

In this study, we consider the public's continuous vaccination to be a three-stage response process. In the case of COVID-19, public responses proceed as follows: motivation, -intention, and -behavior. In other words, this process goes from psychological perception to behavioral intention and then from behavioral intention to actual behavior. To explore this response process, we analyze the public's feelings and experiences related to the COVID-19 pandemic. The theoretical contribution of this research is to construct a theoretical model that can evaluate continuous vaccination for COVID-19 based on the HAPA Model, ECM, and the VH theory. In this model, we explore which factors can produce a significant effect on the public's continuous vaccination in the case of COVID-19. This model reflects the response process of the public's continuous vaccination in the case of COVID-19.

\section{Theoretical background and research hypotheses}

\section{HAPA Model}

The HAPA model is a well-established theoretical model in the field of health behaviors in the past 20 years. This model was first proposed by Schwarzer in 1992 based on the social cognition theory, the rational behavior theory, and the theory of will [4]. The HAPA model divides human health behavior into three stages: pre-intention stage, intention stage, and action stage. Specifically, the pre-intention stage means that the individuals are aware of the danger of not taking a certain health behavior and firmly believe that they have the ability to take this behavior, so as to form the behavior intention [4]. This stage includes three variables: action self-efficacy, outcome expectation, and risk perception. The intention stage refers to the individuals belief that they can deal with various obstacles when taking some behavior then promote them to make a behavior plan and try to do so [4]. Maintenance self-efficacy and planning are the main variables at this stage. The action stage indicates actions produced by the individuals under 
the regulation of self-efficacy, as well as the withdrawal, maintenance, and recovery of this action [4]. Recovery self-efficacy is the main variable at this stage.

In the present study, in order to evaluate the impact process of continuous vaccination of the COVID-19 vaccine, we used the components and variables from the HAPA model and designed a theoretical model that has three stages in sequence: motivation, intention, and behavior. Our theoretical model illustrates the entire response process of individual continuous vaccination. In the motivation stage, we evaluate individuals' perceptions of the harms of unhealthy behaviors related to COVID-19 and assess whether they are capable of taking on healthy behaviors. This stage includes three variables: risk perception, perceived self-efficacy, and outcome expectancy. In particular, risk perception reflects an individual's subjective feelings about the possibility and severity of the harm caused by COVID-19. Perceived selfefficacy denotes the evaluation of an individual's ability to adopt healthy behaviors during the epidemic. Outcome expectancy is an individual's judgment of the possible consequences of taking on certain healthy behaviors. The intention stage is to measure the subjective intention of the individual to adopt the COVID-19 vaccine, including the vaccination intention, social positive cues, and $\mathrm{VH}$. It is worth noting that social positive cues and $\mathrm{VH}$ are the positive and negative factors that affect vaccination, respectively, while vaccination intention is the dependent variable of this stage, which indicates the individual's intention to pursue vaccination. The third stage of the model is the behavior stage, which is used to reflect the actual behavior of individual vaccination. This stage holds four variables: vaccination behavior, perceived usefulness, satisfaction, and continuous vaccination. The specific content of these four variables will be introduced and explained in the ECM.

\section{ECM}

The ECM was first proposed by Oliver in 1980. It was originally designed to understand consumers' purchase behaviors [5]. According to this model, whether consumers buy the same product again depends on the consumers' satisfaction with the purchased product, and this satisfaction is the difference between the expected benefit of the product before the purchase and the actual benefit after the purchase [6]. The ECM is composed of four variables: perceived usefulness, satisfaction, confirmation, and continual use intention. The relationship among the variables is shown as follows. Confirmation affects both satisfaction and perceived usefulness. In addition, perceived usefulness has an impact on satisfaction and continual use intention, respectively, while satisfaction directly affects continual use intention [7].

In this study, we believe that the ECM can be used to explain the continuous vaccination of the COVID-19 vaccine. The main reason is that the process of individual formation of continuous vaccination is similar to the process in ECM. Specifically, after an individual is vaccinated for the first time, an initial expectation of the COVID-19 vaccine and vaccination will be formed. Secondly, after a period of experience and evaluation, the individual will develop various feelings about the COVID-19 vaccine and vaccination. Finally, an individual with positive feelings will have the vaccination behavior again, while others with negative feelings will stop subsequent vaccinations. In this research, we measure the above 
process using four variables: vaccination behavior, perceived usefulness, satisfaction, and continuous vaccination. Vaccination behavior means the actual behavior of an individual accepting the COVID-19 vaccine for the first time. Perceived usefulness refers to the individual's belief that the COVID-19 vaccine will help them after a period of vaccination experience. In addition, satisfaction is an individual's feeling of satisfaction after vaccination. Continuous vaccination indicates the actual action of an individual who has accepted the COVID-19 vaccine to continue to accept it in the future.

\section{$\mathrm{VH}$ theory}

$\mathrm{VH}$ refers to a delay in acceptance or refusal of vaccination despite availability of vaccination services [8]. In 2019, the World Health Organization (WHO) listed VH as one of the top 10 threats to global health [9]. Today, $\mathrm{VH}$ is a global trend, with approximately $90 \%$ of countries across the globe reporting this situation [10]. $\mathrm{VH}$ is a complex phenomenon and varies with place, time, and vaccines. According to the $\mathrm{VH}$ theory, $\mathrm{VH}$ can affect the individual's acceptance of vaccination, which directly leads to the reduction of vaccination coverage and population immunity [11]. It could hinder the complete implementation of the immunization program and increase the risk of preventable disease outbreaks and epidemics [12]. At present, many studies have shown that complacency, convenience and confidence were the three main factors affecting $\mathrm{VH}[10,13]$.

Since the COVID-19 vaccine was developed as recently as 2020, some questions about its side effects, efficacy, and rigorousness are still being raised by the public, which will lead to $\mathrm{VH}$. We therefore take the important factor of $\mathrm{VH}$ into the theoretical model and analyze its impact on vaccination intention. Based on Quinn's research (2019) [13], we use three second-order factors of complacency, convenience, and confidence to measure VH. In particular, complacency denotes that an individual believes that the COVID19 vaccine is unnecessary or worthless. Convenience is the availability of the COVID-19 vaccine, and confidence indicates an individual's lack of trust in the COVID-19 vaccine or its providers.

\section{Impacts of motivation stage on intention stage}

The outcome expectancy is the hypothesis of various possible outcomes of an individual's health behavior before taking action, including positive and negative outcome expectancy [14]. According to the HAPA model, for health behavior, the individual expects to maximize its positive outcomes and minimize its negative outcomes [15]. Currently, many studies have shown that positive outcome is expected to predict behavior intention [16]. In the context of COVID-19, vaccination intention is an effective health protection behavior intention. In this sense, the positive outcome of this behavior is obvious. Therefore, we propose the following hypothesis:

H1: Outcome expectancy has a positive significant impact on vaccination intention.

Risk is a key factor affecting behavior intention. According to the research of Bhattacherjee and Shrivastava (2018) [17], when individuals implement a certain behavior, they often fail to implement or terminate the implementation due to perceived risks. In the process of vaccination, the individual's vaccination intention is a kind of risk behavior intention after a psychological judgment. When individuals 
subjectively believe that the risk and cost of this behavior are high, their willingness to implement it will be greatly reduced [18]. Currently, the side effects, efficacy, rigorousness, and other issues of the COVID19 vaccine have not eliminated individuals' doubts about its risks. Therefore, we propose the following hypothesis:

H2: Risk perception has a negative significant impact on vaccination intention.

The HAPA model indicates that if individuals expect a positive outcome of health behaviors, they will be more likely to take on these behaviors [19]. During this process, an individual will exert perceived selfefficacy by evaluating the positive outcome of behavior. At present, several recent studies have indicated that an individual's perceived self-efficacy can positively influence behavior intention [20]. In the context of COVID-19, vaccination is an effective way to protect health. Therefore, individuals' perceived selfefficacy on the positive outcome of this behavior can stimulate their vaccination intention. Therefore, we propose the following hypothesis:

H3: Perceived self-efficacy has a positive significant impact on vaccination intention.

\section{Impacts of intention stage on behavior stage}

Previous studies have demonstrated that social positive cues have a significant positive impact on an individual's behavioral intentions [21, 22]. In the context of COVID-19, the doctor's recommendations and vaccination reports are social positive cues to vaccine adoption. In accordance with the conclusions of existing research, we argue that social positive cues can motivate the public to vaccinate and to promote behavioral intention conducive to vaccination. Therefore, we propose the following hypothesis:

H4: Social positive cues have a positive significant impact on vaccination intention.

$\mathrm{VH}$ theory believes that $\mathrm{VH}$ is a comprehensive manifestation of individual gender, age, culture, religious beliefs, and other factors [23]. In recent years, with the rise of various anti-vaccine behaviors, $\mathrm{VH}$ has also produced a non-negligible influence on vaccination intention. At present, studies have shown that VH has a negative significant effect on behavior intention $[13,24]$. In the context of COVID-19, Sallam et al. (2021) [23] indicated that VH was related to the COVID-19 vaccination. The similar conclusion was also confirmed by the research of Kwok et al. (2021) [25]. Therefore, based on the above argument, we propose the following hypothesis:

$\mathrm{H5}$ : VH has a negative significant impact on vaccination intention.

The HAPA model proves that intention has a positive significant impact on behavior [4]. In fact, the effect from intention to behavior is also a specific process from individual decision-making to implementation, and there is an inevitable connection between the two phases [26]. Moreover, the positive impact of intention on behavior can be supported by other classic theories and models, such as the Theory of Planned Behavior [27]. In terms of vaccination, we also believe that vaccination intention can positively affect vaccination behavior. Therefore, we propose the following hypothesis: 
H6: Vaccination intention has a positive significant impact on vaccination behavior.

\section{Impacts in the behavior stage}

In the ECM, confirmation can have a direct impact on perceived usefulness and satisfaction [5]. Moreover, many previous studies have also verified that confirmation can positively affect perceived usefulness [28] and satisfaction [29]. The actual behavior can achieve the comparison of individual expectations and experiences, and it is a process by which individual expectations are confirmed in the actual process [30]. We believe that this argument can also be applied to COVID-19. The public compares their own experience of vaccination with their own expectations after vaccination behavior. If their expectations are confirmed, they will feel that the vaccination is useful and be satisfied with vaccination. Therefore, we propose the following hypotheses:

H7: Vaccination behavior has a positive significant impact on perceived usefulness.

H8: Vaccination behavior has a positive significant impact on satisfaction.

In the ECM, when individuals adopt a certain behavior, they will continuously evaluate their perception of their own behavior then guide their emotions and subsequent behaviors [5]. Bhattacherjee, Perols, and Sanford (2008) [31] believed that perceived usefulness was regarded as a degree of utilitarianism to improve work performance, which was a long-term belief that combined expectations. According to this point of view, given that individuals have the tendency to subconsciously pursue behaviors or strive for external rewards, perceived usefulness is the decisive factor influencing individual emotions and subsequent behaviors. At present, most studies have demonstrated that perceived usefulness has a direct impact on individual satisfaction [32] and continuous behaviors [33]. As far as vaccination is concerned, if the public has a high evaluation of the perceived usefulness of vaccination, then their satisfaction with vaccination will increase and they are likely to continue vaccination. Therefore, we propose the following hypotheses:

H9: Perceived usefulness has a positive significant impact on satisfaction.

H10: Perceived usefulness has a positive significant impact on continuous vaccination.

The ECM believes that satisfaction is an important variable for predicting continued use intentions and behaviors [5]. Many scholars, working in various fields, have proven that satisfaction has a positive effect on continued use intentions and behaviors [28,34]. In addition, from the perspective of rational people, individuals are more willing to continue to use products or services that are useful to them and that satisfy them [35]. We believe that this evidence can also be applied in the context of COVID-19. The more satisfied the public is with vaccination, the more they tend to continue vaccination. Therefore, we propose the following hypothesis:

H11: Satisfaction has a positive significant impact on continuous vaccination.

In view of the above hypotheses, we construct the theoretical model of this study in Fig. 1. 


\section{Methods}

\section{Participants}

We selected as subject citizens of China who have been vaccinated; this was due to three reasons. First, China has been studying the COVID-19 vaccine since March 2020. In June 2020, the country started its first clinical trial of the COVID-19 vaccine. In addition, China officially joined the COVID-19 Vaccine Global Access in October 2020 and began administering COVID-19 vaccinations at the end of 2020 [3]. In this sense, China was one of the world's leading countries in the development of the COVID-19 vaccine; therefore, we expected to obtain high-quality data from this country. Second, as of July 7, 2021, the number of COVID-19 vaccinations in China has exceeded 1.32 billion doses [3], making data collection in this country optimal for obtaining sufficient and effective samples. Third, the Chinese government adopted the principle of voluntary rather than compulsory vaccination during the process of COVID-19 vaccinations. Each Chinese citizen can choose whether or not to vaccinate according to his or her preferences; in this respect, the policy environment of China meets the basic requirements for continuous vaccination as outlined in this research.

\section{Measures}

In this study, we designed 32 measurement items to measure the 12 variables in the theoretical model. The scale was designed as a 7-point Likert scale in which "1" represented a measure of strongly disagreement and "7" denoted strongly agreement. All items are shown in Table 1. The content of each item was designed with reference to prior valid measures. We refined the survey contents of the scale to obtain high-quality data. Throughout the investigation, all items were conducted in Chinese. 
Table 1

Specific measurement items of the scale

\begin{tabular}{|c|c|c|c|}
\hline Variables & \multicolumn{2}{|l|}{ Items } & References \\
\hline \multirow{3}{*}{$\begin{array}{l}\text { Outcome expectancy } \\
\text { (OE) }\end{array}$} & \multicolumn{2}{|c|}{ OE1: If I get vaccinated, I will feel healthier. } & [14] \\
\hline & \multicolumn{2}{|c|}{ OE2: If I get vaccinated, I will feel better mentally. } & \\
\hline & \multicolumn{2}{|c|}{ OE3: If I get vaccinated, I will have fewer health problems. } & \\
\hline \multirow[t]{4}{*}{ Risk perception (RP) } & \multicolumn{2}{|c|}{ RP1: I am concerned about the vaccine efficacy. } & [36] \\
\hline & \multicolumn{2}{|c|}{ RP2: I am concerned about the vaccine side effects. } & \\
\hline & \multicolumn{2}{|c|}{ RP3: I am concerned about the vaccine rigor of testing. } & \\
\hline & \multicolumn{2}{|c|}{ RP4: I am concerned that I may be allergic to the vaccine. } & \\
\hline \multirow[t]{2}{*}{$\begin{array}{l}\text { Perceived self-efficacy } \\
\text { (PS) }\end{array}$} & \multicolumn{2}{|c|}{$\begin{array}{l}\text { PS1: I am certain that I can get vaccinated, even if I have to } \\
\text { mobilize myself. }\end{array}$} & [4] \\
\hline & \multicolumn{2}{|c|}{$\begin{array}{l}\text { PS2: I am certain that I can get vaccinated, even if it is } \\
\text { difficult. }\end{array}$} & \\
\hline \multirow{3}{*}{$\begin{array}{l}\text { Social positive cues } \\
\text { (SPC) }\end{array}$} & \multicolumn{2}{|c|}{ SPC1: I will get vaccinated when the doctor recommends it. } & [36] \\
\hline & \multicolumn{2}{|c|}{$\begin{array}{l}\text { SPC2: I will get vaccinated when vaccination becomes } \\
\text { popular. }\end{array}$} & \\
\hline & \multicolumn{2}{|c|}{$\begin{array}{l}\text { SPC3: I will get vaccinated when I know enough about } \\
\text { vaccine. }\end{array}$} & \\
\hline \multirow{6}{*}{$\begin{array}{l}\text { Vaccine hesitancy } \\
\text { (VH) }\end{array}$} & \multirow[t]{2}{*}{ Confidence (CF) } & CF1: I think the vaccine is not safe. & \multirow[t]{6}{*}{ [13] } \\
\hline & & CF2: I think the vaccine is not effective. & \\
\hline & \multirow[t]{2}{*}{$\begin{array}{l}\text { Complacency } \\
\text { (CP) }\end{array}$} & $\begin{array}{l}\text { CP1: I think the vaccine is not } \\
\text { important. }\end{array}$ & \\
\hline & & $\begin{array}{l}\text { CP2: I think the vaccine is not } \\
\text { necessary. }\end{array}$ & \\
\hline & \multirow[t]{2}{*}{ Convenience (CV) } & $\begin{array}{l}\text { CV1: I think the vaccine is not } \\
\text { convenient. }\end{array}$ & \\
\hline & & CV2: I think the vaccine is not free. & \\
\hline \multirow[t]{3}{*}{$\begin{array}{l}\text { Vaccination intention } \\
\text { (VI) }\end{array}$} & \multicolumn{2}{|c|}{$\begin{array}{l}\text { VI1: I intend to get all doses of the vaccine during the } \\
\text { vaccination period. }\end{array}$} & [37] \\
\hline & \multicolumn{2}{|c|}{$\begin{array}{l}\text { VI2: I will try to get all doses of the vaccine during the } \\
\text { vaccination period. }\end{array}$} & \\
\hline & \multicolumn{2}{|c|}{$\begin{array}{l}\text { VI3: I plan to get all doses of the vaccine during the } \\
\text { vaccination period. }\end{array}$} & \\
\hline $\begin{array}{l}\text { Vaccination behavior } \\
\text { (VB) }\end{array}$ & \multicolumn{2}{|c|}{ VB1: I often get vaccinated during the vaccination period. } & [38] \\
\hline
\end{tabular}




\begin{tabular}{|c|c|c|}
\hline Variables & Items & References \\
\hline & $\begin{array}{l}\text { VB2: I get all doses of the vaccine during the vaccination } \\
\text { period. }\end{array}$ & \\
\hline \multirow[t]{3}{*}{ Satisfactory (SAT) } & SAT1: Overall, I am satisfied with the vaccine. & \multirow[t]{3}{*}{ [39] } \\
\hline & $\begin{array}{l}\text { SAT2: The vaccine I am currently getting meets my } \\
\text { expectations. }\end{array}$ & \\
\hline & $\begin{array}{l}\text { SAT3: I am very pleased with my experience with getting } \\
\text { vaccinated. }\end{array}$ & \\
\hline \multirow{3}{*}{$\begin{array}{l}\text { Continuous } \\
\text { vaccination (CVN) }\end{array}$} & CVN1: I am likely to continue to get vaccinated in the future. & \multirow[t]{3}{*}{ [39] } \\
\hline & CVN2: I intend to consistently get vaccinated in the future. & \\
\hline & $\begin{array}{l}\text { CVN3: I intend to continue getting vaccinated rather than } \\
\text { discontinue the vaccine. }\end{array}$ & \\
\hline \multirow{3}{*}{$\begin{array}{l}\text { Perceived usefulness } \\
\text { (PU) }\end{array}$} & PU1: I think that vaccine is useful for my life. & \multirow[t]{3}{*}{ [39] } \\
\hline & PU2: Getting vaccinated improves my health. & \\
\hline & $\begin{array}{l}\text { PU3: Getting vaccinated helps me conveniently perform } \\
\text { many tasks. }\end{array}$ & \\
\hline
\end{tabular}

\section{Data collection}

A pilot survey was deployed to evaluate whether the scale was suitable for studying vaccine adoption. The results of the analysis showed that the scale was suitable for studying continuous vaccination. In addition, due to the effects of missing values, we used only "gender", "age", "education" and "province" as survey variables in our investigation of personal attribute information.

The formal investigation was based on Chinese samples. Given the feasibility and practical operability of surveys, we posted our questionnaires on the Sojump website (http://www.sojump.com/), a specialized online survey system in China similar to Qualtrics.com or SurveyMonkey.com in the United States. We selected registered members of Sojump as our target population. The website currently has over 60 million registered members who are located in various provinces across China. An advertisement for the survey was posted for one week on public forums. To improve the quality of our data, we charged five Chinese yuan for each respondent to participate. Participation was completely anonymous. Regardless of whether someone chose to participate, there was no risk of loss. To protect respondents' privacy, "gender" and "province" were set as the nominal variables, while "age" and "education" were set as ordinal variables. The entire investigation period lasted one month (from May 10, 2021, to June 9, 2021). We applied the following screening item: Have you been vaccinated? Respondents who had not been vaccinated were not used as research samples. In addition, when screening the questionnaires, we deleted some samples of responses that were obviously unreasonable. Moreover, samples with a large number of missing values were excluded. In total, 768 members participated in the study. The effective 
sample included 561 individuals after the data screening. Table 2 provides more detailed descriptive statistics.

Table 2

Descriptive statistics of the respondents' characteristics

\begin{tabular}{|c|c|c|c|}
\hline Demographics & Category & Frequency & Percentage \\
\hline \multirow[t]{2}{*}{ Gender } & Male & 269 & 48.0 \\
\hline & Female & 292 & 52.0 \\
\hline \multirow[t]{5}{*}{ Age } & $\leq 20$ & 56 & 10.0 \\
\hline & $21-30$ & 198 & 35.3 \\
\hline & $31-40$ & 176 & 31.4 \\
\hline & $41-50$ & 107 & 19.0 \\
\hline & $\geq 50$ & 24 & 4.3 \\
\hline \multirow[t]{4}{*}{ Education } & High school or below & 32 & 5.7 \\
\hline & Junior college & 88 & 15.7 \\
\hline & University & 284 & 50.6 \\
\hline & Master's degree or higher & 157 & 28.0 \\
\hline \multirow[t]{9}{*}{ Province } & Shandong & 78 & 13.9 \\
\hline & Henan & 70 & 12.5 \\
\hline & Chongqing & 61 & 10.9 \\
\hline & Hunan & 60 & 10.7 \\
\hline & Sichuan & 57 & 10.2 \\
\hline & Heilongjiang & 55 & 9.8 \\
\hline & Guangdong & 43 & 7.6 \\
\hline & Jiangsu & 34 & 6.0 \\
\hline & Others & 103 & 18.4 \\
\hline
\end{tabular}

\section{Results}

\section{Reliability and validity test}

Before hypothesis testing, the reliability and validity of the scale were tested. Using SPSS 17.0 and Lisrel 8.7 software, we conducted an exploratory factor analysis. In a series of analysis results, the KMO value 
was 0.89 , which suggests that the sample data were suitable for factor analysis [40]. Furthermore, this analysis extracted 12 factors that explained $88.66 \%$ of total variance, which indicates that these factors represent most of the information of the 32 items [41]. In addition, the factor loadings of all 32 items were not less than 0.7 , which demonstrates that these items can be analyzed for reliability and validity [42]. Table 3 shows the specific factor loading of each item. 
Table 3

Statistical results of some indicators

\begin{tabular}{|c|c|c|c|c|c|c|}
\hline \multicolumn{2}{|c|}{ Factors } & Items & Loadings & AVE & CR & Cronbach a \\
\hline \multirow{3}{*}{\multicolumn{2}{|c|}{$\mathrm{OE}$}} & OE1 & 0.80 & \multirow[t]{3}{*}{0.68} & \multirow[t]{3}{*}{0.87} & \multirow[t]{3}{*}{0.91} \\
\hline & & OE2 & 0.83 & & & \\
\hline & & OE3 & 0.85 & & & \\
\hline \multirow{4}{*}{\multicolumn{2}{|c|}{ RP }} & RP1 & 0.88 & \multirow[t]{4}{*}{0.80} & \multirow[t]{4}{*}{0.94} & \multirow[t]{4}{*}{0.93} \\
\hline & & RP2 & 0.92 & & & \\
\hline & & RP3 & 0.92 & & & \\
\hline & & RP4 & 0.86 & & & \\
\hline \multirow{2}{*}{\multicolumn{2}{|c|}{ PS }} & PS1 & 0.77 & \multirow[t]{2}{*}{0.59} & \multirow[t]{2}{*}{0.74} & \multirow[t]{2}{*}{0.89} \\
\hline & & PS2 & 0.77 & & & \\
\hline \multirow{3}{*}{\multicolumn{2}{|c|}{ SPC }} & SPC1 & 0.71 & \multirow[t]{3}{*}{0.52} & \multirow[t]{3}{*}{0.76} & \multirow[t]{3}{*}{0.94} \\
\hline & & SPC2 & 0.72 & & & \\
\hline & & SPC3 & 0.73 & & & \\
\hline \multirow[t]{6}{*}{ VH } & \multirow[t]{2}{*}{ CF } & CF1 & 0.78 & \multirow[t]{2}{*}{0.62} & \multirow[t]{2}{*}{0.76} & \multirow[t]{2}{*}{0.95} \\
\hline & & CF2 & 0.79 & & & \\
\hline & \multirow[t]{2}{*}{$\mathrm{CP}$} & $\mathrm{CP} 1$ & 0.81 & \multirow[t]{2}{*}{0.63} & \multirow[t]{2}{*}{0.77} & \multirow[t]{2}{*}{0.95} \\
\hline & & $\mathrm{CP} 2$ & 0.78 & & & \\
\hline & \multirow[t]{2}{*}{ CV } & CV1 & 0.78 & \multirow[t]{2}{*}{0.55} & \multirow[t]{2}{*}{0.71} & \multirow[t]{2}{*}{0.84} \\
\hline & & CV2 & 0.70 & & & \\
\hline \multirow{3}{*}{\multicolumn{2}{|c|}{ VI }} & VI1 & 0.73 & \multirow[t]{3}{*}{0.55} & \multirow[t]{3}{*}{0.79} & 0.97 \\
\hline & & VI2 & 0.75 & & & \\
\hline & & VI3 & 0.75 & & & \\
\hline VB & & VB1 & 0.88 & 0.76 & 0.86 & 0.98 \\
\hline & & VB2 & 0.86 & & & \\
\hline SAT & & SAT1 & 0.76 & 0.53 & 0.77 & 0.95 \\
\hline $\begin{array}{l}\text { Note: } \\
\text { positiv } \\
\text { vaccin } \\
P U=p\end{array}$ & & $\begin{array}{l}\text { expect } \\
\text { raccine } \\
\text { n; VB = } \\
\text { ulness. }\end{array}$ & $\begin{array}{l}P=\text { risk perc } \\
\text { cy; } C F=\text { co } \\
\text { tion behav }\end{array}$ & $\begin{array}{l}S=\text { per } \\
C P=C \\
\text { satisf }\end{array}$ & $\begin{array}{l}\text { self-e } \\
\text { cency } \\
\text {; CVN }\end{array}$ & $\begin{array}{l}\text {; } \text { SPC = social } \\
\text { convenience; } \mathrm{VI}= \\
\text { nuous vaccination; }\end{array}$ \\
\hline
\end{tabular}




\begin{tabular}{|c|c|c|c|c|c|}
\hline Factors & Items & Loadings & AVE & CR & Cronbach a \\
\hline & SAT2 & 0.73 & & & \\
\hline & SAT3 & 0.70 & & & \\
\hline \multirow[t]{3}{*}{ CVN } & CVN1 & 0.81 & 0.70 & 0.88 & 0.96 \\
\hline & CVN2 & 0.87 & & & \\
\hline & CVN3 & 0.83 & & & \\
\hline \multirow[t]{3}{*}{ PU } & PU1 & 0.75 & 0.55 & 0.78 & 0.94 \\
\hline & PU2 & 0.73 & & & \\
\hline & PU3 & 0.74 & & & \\
\hline \multicolumn{6}{|c|}{$\begin{array}{l}\text { Note: } \mathrm{OE}=\text { outcome expectancy; } \mathrm{RP}=\text { risk perception; } \mathrm{PS}=\text { perceived self-efficacy; } \mathrm{SPC}=\text { social } \\
\text { positive cues; } \mathrm{VH}=\mathrm{vaccine} \text { hesitancy; } \mathrm{CF}=\text { confidence; } \mathrm{CP}=\text { complacency; } \mathrm{CV}=\text { convenience; } \mathrm{VI}= \\
\text { vaccination intention; } \mathrm{VB}=\text { vaccination behavior; } \mathrm{SAT}=\text { satisfactory; } \mathrm{CVN}=\text { continuous vaccination; } \\
\mathrm{PU}=\text { perceived usefulness. }\end{array}$} \\
\hline
\end{tabular}

The composite reliability (CR) values and Cronbach a values were used to evaluate the reliability of the scale. Detailed analysis results are shown in Table 3. Based on this table, it can be seen that $\mathrm{CR}$ values and Cronbach a values of all factors exceeded 0.7, which indicates that the scale had high reliability [43].

In the validity test, we intended to test the convergent validity and discriminant validity of the scale respectively. The average variance extracted (AVE) was used to analyze the convergent validity. The analysis results were also shown in Table 3 We can see that all AVE values were greater than 0.5 , which demonstrates that this scale had satisfactory convergent validity [44]. In addition, the confirmatory factor analysis (CFA) was used to test the discriminant validity of the scale. After the CFA, we discovered that the square roots of AVE values were greater that these coefficients, which indicates that the discriminant validity of the scale meets the requirements for analysis [45].

\section{Hypothesis tests}

Using Lisrel 8.7 software, structural equation modelling was used to test our hypotheses. The analysis results of this model are shown in Table 4 . We learned that all the fit indices results were acceptable, which demonstrates that our hypothesis tests that are used in this model were reasonable and effective [45]. 
Table 4

Fitting Indices and Evaluation Criteria of Research Model

\begin{tabular}{|lllllllllll|}
\hline Fitting indices & \multicolumn{4}{c}{ Absolutely indices } & \multicolumn{3}{c|}{$\begin{array}{c}\text { Parsimony } \\
\text { indices }\end{array}$} & \multicolumn{3}{c|}{ Incremental indices } \\
\cline { 2 - 12 } & $\chi^{2} / d f$ & GFI & AGFI & RMSEA & PNFI & PGFI & CFI & NFI & IFI \\
\hline Values of fitting indices & 2.76 & 0.90 & 0.82 & 0.07 & 0.87 & 0.72 & 0.98 & 0.98 & 0.98 \\
$\begin{array}{l}\text { Evaluation criteria } \\
\text { values [45] }\end{array}$ & $<3$ & $>$ & $>0.8$ & $<0.08$ & $>0.5$ & $>0.5$ & $>$ & $>$ & $>$ \\
\hline
\end{tabular}

Figure 2 shows the model's normalized path coefficients. In the motivation stage, we learned that perceived self-efficacy had a positive significant influence on vaccination intention $(\beta=0.1, p<0.05)$, but this effect did not appear in the relationship between outcome expectancy and vaccination intention ( $\beta=$ $0.04, p>0.05)$ and between risk perception and vaccination intention $(\beta=0.03, p>0.05)$. Therefore, $\mathrm{H} 3$ was supported, but $\mathrm{H} 1$ and $\mathrm{H} 2$ were not. In the intention stage, we found that social positive cues $(\beta=$ $0.13, p<0.01)$ and VH $(\beta=-0.67, p<0.001)$ exerted a positive and negative significant impact on vaccination intention, respectively, which supports $\mathrm{H} 4$ and $\mathrm{H} 5$. Moreover, vaccination intention positively affected vaccination behavior significantly $(\beta=0.75, p<0.001)$, so H6 was supported. In the behavior stage, we noted that vaccination behavior had a significantly positive impact on perceived usefulness ( $\beta$ $=0.62, p<0.001)$ and satisfaction $(\beta=0.26, p<0.001)$, respectively. Thus, $\mathrm{H} 7$ and $\mathrm{H} 8$ were supported. In addition, perceived usefulness produced a positive significant influence on satisfaction $(\beta=0.73, p<$ $0.001)$ and continuous vaccination $(\beta=0.88, p<0.001)$, respectively. Thus, $\mathrm{H} 9$ and $\mathrm{H} 10$ were supported. However, the positive effect of satisfaction on continuous vaccination was not significant $(\beta=-0.06, p>$ 0.05), so H11 was not supported.

\section{Discussion}

By combining the HAPA model, ECM, and VH theory, we produced a theoretical model that explores the impact process of continuous vaccination in COVID-19 and obtained six valuable conclusions.

\section{Implications}

First, perceived self-efficacy has a positive significant impact on vaccination intention, but the effects of outcome expectancy and risk perception on vaccination intention are not significant. This conclusion is not completely consistent with the views in the HAPA model, in which the three variables-that is, outcome expectancy, risk perception, and perceived self-efficacy - are all pre-factors of behavioral intention [4]. However, in the context of COVID-19, the roles of outcome expectancy and risk perception have not been demonstrated. We believe that one possible reason for this result is that this study is an empirical analysis carried out in China; at present, China is one of the few countries where the global epidemic is well controlled, so in this region, the public's concern about COVID-19 is not as serious as 
when the virus first broke out. Conversely, the public does not feel safe about the newly developed COVID19 vaccine. In other words, vaccination may not be the safest health behavior in the minds of the Chinese public. Therefore, in the context of COVID-19, only the effect of perceived self-efficacy on behavioral intention has been proven.

Second, social positive cues have a positive significant influence on vaccination intention. This conclusion is similar to the evidence obtained from existing studies [21, 22]. In an environment where vaccination is questioned by the public at this stage, reliable knowledge, suggestions, and information are important guidelines for determining the intention of public behavior. The results of our analysis show that social positive cues are important elements that affect the public's behavioral intentions. However, combining the third conclusion, based on the values of path coefficient, we conclude that compared with $\mathrm{VH}$, social positive cues have a relatively limited effect on behavioral intention. This also shows that the public still holds, to a certain extent, a variety of concerns about vaccination.

Third, VH has a negative significant influence on vaccination intention. This conclusion is consistent with existing studies $[13,24]$ and illustrates a dilemma for COVID-19 vaccine at this stage. China was one of the first countries in the world to develop the COVID-19 vaccines and has recently exported them; however, due to fewer clinical trials, side effects, effectiveness, and other reasons, the COVID-19 vaccines still have not been fully recognized in the public mind. Although China implements a free vaccination policy for the public, the value of path coefficient shows that the negative impact of $\mathrm{VH}$ on vaccination intention is still great.

Fourth, vaccination behavior produces a positive significant effect on perceived usefulness and satisfaction, respectively. This conclusion is completely consistent with the views in ECM [5]. According to the first and third conclusions of this study, we can conclude that the public's recognition of the COVID19 vaccine is not high. However, the empirical analysis results show that when the public is vaccinated, they find that their own expectations can be confirmed. So far, there have been no cases of adverse reactions due to vaccination in China. Moreover, the vaccinated public has a reliable health code, which allows them to more freely and safely enter some public places. The public can not only perceive the usefulness of the vaccine, but also feel satisfied with the vaccination process and experience. This indicates to some extent that the COVID-19 vaccine is not so bad at this stage.

Fifth, perceived usefulness exerted a positive significant impact on satisfaction and continuous vaccination, respectively. This conclusion can be used as a supplement to previous research findings [32, 33]. Similar to other vaccines, the public's perception of the usefulness of the COVID-19 vaccine can not only enhance their satisfaction, but also prompt them to be vaccinated again. Moreover, based on the values of path coefficient, we can see that the positive impact of perceived usefulness is prominent. This explains that the perceived usefulness of the COVID-19 is an important factor affecting public emotions and subsequent behaviors.

Sixth, satisfaction has no positive significant influence on continuous vaccination. This conclusion is different from previous research [28,34], and it indicates the particularity of the COVID-19 vaccine. We 
speculate that the main reason for this conclusion is that vaccination is a comprehensive behavior that is affected by various factors such as gender, age, region, culture, and religion. Satisfaction may influence several of these factors, but these impacts are not enough to contribute to continuous vaccination. We did not examine the impact of VH on continuous vaccination in the behavior stage, but based on the factor loadings of the VH variable in the intention stage, we find that the public's VH mainly focuses on confidence and complacency. In fact, complacency may play a potential role in continuous vaccination.

In addition, the present study makes some practical contributions. First, governments of various countries need to strengthen all types of vaccination publicity. In this regard, it is best for relevant departments to publicize the benefits of the health behavior of vaccination through typical case interviews and experimental reports, so as to enhance the public's perceived self-efficacy of vaccination. At the same time, doctors' recommendations and popularization of vaccination knowledge can also used to be stimulate the public to vaccinate. In addition, it is necessary to minimize the public's VH. An effective approach would be to ask groups that have been vaccinated to highlight the safety and necessity of vaccination in order to help increase public confidence and reduce complacency for vaccination. The above practices will have a positive impact on the public's vaccination. Second, government and related policy-making institutions should take full advantage of the perceived usefulness of vaccination; in this regard, medical research departments need to strengthen clinical exploration of vaccination and constantly strive to improve the effect of vaccination, so that the public can experience the usefulness of vaccines in protecting physical and mental health. In addition, government should also ensure convenience and provide benefits to the vaccinated public. For instance, in terms of travel, shopping, and medical services, relevant departments can provide certain priorities and discounts for vaccinated groups so that they can really feel the usefulness of vaccination. The above measures will prompt the vaccinated population to get vaccinated again in the future.

\section{Limitations and future directions}

A major limitation of this study is that we conducted data collection in China. COVID-19 in China is longer as serious as it was during the start of the pandemic. Moreover, vaccine development in this country is at the forefront of the world, according to the rates of vaccination. Therefore, the findings of this study may not be applicable to those countries where the epidemic is severe and vaccination technology is not as advanced, such as India. In addition, we find that VH has a negative significant impact on vaccination intention for the first time. So, does this variable have a similar effect on continuous vaccination? Researchers can explore this issue in the future.

\section{Conclusions}

Vaccination for the COVID-19 provides an effective approach for the general improvement of social safety and individual health. To date, few studies have analyzed the continuous vaccination for COVID-19 vaccine and its impact process. Using the HAPA Model, ECM and VH theory, this research evaluates the continuous vaccination for COVID-19. The respondents in this study were individuals in China who have been vaccinated. Six valuable and novel findings are identified through this research. First, perceived 
efficacy has a positive significant impact on vaccination intention, but the positive effects of outcome expectancy and risk perception on vaccination intention are not significant. Second, social positive cues have a positive significant influence on vaccination intention. Third, VH has a negative significant influence on vaccination intention. Four, vaccination behavior produces a positive significant effect on perceived usefulness and satisfaction, respectively. Five, perceived usefulness exerted a positive significant impact on satisfaction and continuous vaccination, respectively. Six, satisfaction has no positive significant influence on continuous vaccination. Our theoretical model, which is the main contribution of this research, indicates that individual continuous vaccination is a process from motivation to intention, and from intention to behavior, and then from behavior to continuous behavior.

\section{Declarations}

\section{Ethical Approval and Consent to participate}

The participants were informed about the purpose and procedures of this study via an advertisement before the investigation. Moreover, participants were voluntary and anonymous throughout the investigation.

\section{Consent for publication}

Not applicable.

\section{Availability of data and materials}

The datasets used during the current study are available from the corresponding author on reasonable request.

\section{Competing interests}

The authors declare that they have no competing interests.

\section{Funding}

Not applicable.

\section{Authors' contributions}

WZH and $Y X$ conceived and designed the study; WZH and $Y X$ conducted analysis and interpreted data; $\mathrm{HZ}$ and $\mathrm{YS}$ collected data; WZH and YX drafted the manuscript and all author contributed to revise it. All 


\section{Acknowledgements}

Not applicable.

\section{References}

1. Khanal P, Devkota N, Dahal M, Paudel K, Joshi D. Mental health impacts among health workers during COVID-19 in a low resource setting: a cross-sectional survey from Nepal. Globalization Health. 2020;16(1):1-12.

2. Ledford H, Cyranoski D, Van Noorden R. The UK has approved a COVID vaccine-here's what scientists now want to know. Nature. 2020;588(7837):205-6.

3. MedSci: Bulletin of global COVID-19 and vaccination on July 7, 2021. [https://www.medsci.cn/article/show_article.do?id=504c21386590]. Accessed 30 July 2021.

4. Schwarzer R, Lippke S, Luszczynska A. Mechanisms of health behavior change in persons with chronic illness or disability: The Health Action Process Approach (HAPA). Rehabil Psychol. 2011;56(3):161-70.

5. Bhattacherjee A. Understanding information systems continuance: An expectation-confirmation model. Mis Quart. 2001;25(3):351-70.

6. Zhang H, Lu Y, Gupta S, Gao P. Understanding group-buying websites continuance: An extension of expectation confirmation model. Internet Res. 2015;25(5):767-93.

7. Lin CS, Wu S, Tsai RJ. Integrating perceived playfulness into expectation-confirmation model for web portal context. Inform Manage. 2005;42(5):683-93.

8. Larson HJ, Jarrett C, Schulz WS, Chaudhuri M, Zhou Y, Dube E, Schuster M, MacDonald NE, Wilson R. Measuring vaccine hesitancy: The development of a survey tool. Vaccine. 2015;33(34):4165-75.

9. The Daily Star. Ten threats to global health in 2019. [https://www.thedailystar.net/health/news/tenthreats-global-health-2019-1693402]. Accessed 30 July 2021.

10. MacDonald NE. Vaccine hesitancy: Definition, scope and determinants. Vaccine. 2015;33(34):41614164.

11. Hotez P. America and Europe's new normal: The return of vaccine-preventable diseases. Pediatr Res. 2019;85:912-14.

12. Piot P, Larson HJ, O’Brien KL, N'kengasong J, Ng E, Sow S, Kampmann B. Immunization: Vital progress, unfinished agenda. Nature. 2019;575(7781):119-29.

13. Quinn SC, Jamison AM, An J, Hancock GR, Freimuth VS. Measuring vaccine hesitancy, confidence, trust and flu vaccine uptake: Results of a national survey of White and African American adults. Vaccine. 2019;37(9):1168-73. 
14. Schwarzer R, Renner B. Social-cognitive predictors of health behavior: Action self-efficacy and coping self-efficacy. Health Psychol. 2000;19(5):487-95.

15. Schwarzer R. Modeling health behavior change: How to predict and modify the adoption and maintenance of health behaviors. Appl Psychol. 2008;57(1):1-29.

16. Schwarzer R, Hamilton K. Changing behavior using the health action process approach. New York: Cambridge University Press; 2020.

17. Bhattacherjee A, Shrivastava U. The effects of ICT use and ICT Laws on corruption: A general deterrence theory perspective. Gov Inform Q. 2018;35(4):703-12.

18. Joveini H, Rohban A, Eftekhar Ardebili H, Dehdari T, Maheri M, Hashemian M. The effects of an education program on hookah smoking cessation in university students: An application of the Health Action Process Approach (HAPA). J Subst Use. 2020;25(1):62-9.

19. Daddario DK. A review of the use of the health belief model for weight management. Medsurg Nurs. 2007;16(6):363-6.

20. Buglar ME, White KM, Robinson NG. The role of self-efficacy in dental patients' brushing and flossing: Testing an extended Health Belief Model. Patient Educ Couns. 2010;78(2):269-72.

21. Rezaei R, Mianaji S. Using the health belief model to understand farmers' intentions to engage in the on-farm food safety practices in Iran. J Agr Sci Tech-Iran. 2019;21(3):561-74.

22. Koloseni DN, Lee CY, Gan ML. Understanding information security behaviours of Tanzanian government employees: A health belief model perspective. Int J Technol Hum In. 2019;15(1):15-32.

23. Sallam M, Dababseh D, Eid H, Al-Mahzoum K, Al-Haidar A, Taim D, Yaseen A, Ababneh N A, Bakri FG, Mahafzah A. High rates of COVID-19 vaccine hesitancy and its association with conspiracy beliefs: A study in Jordan and Kuwait among other Arab countries. Vaccines-Basel. 2021;9(1):42.

24. Xiao X, Wong RM. Vaccine hesitancy and perceived behavioral control: A meta-analysis. Vaccine. 2020;38(33):5131-8.

25. Kwok KO, Li KK, Wei WI, Tang A, Wong SYS, Lee SS. Influenza vaccine uptake, COVID-19 vaccination intention and vaccine hesitancy among nurses: A survey. Int J Nurs Stud. 2021;114:103854.

26. Wang YS, Shih YW. Why do people use information kiosks? A validation of the Unified Theory of Acceptance and Use of Technology. Gov Inform Q. 2009;26(1):158-65.

27. Ajzen I. The theory of planned behavior. Organ Behav Hum Dec. 1991;50(2):179-211.

28. Veeramootoo N, Nunkoo R, Dwivedi YK. What determines success of an e-government service? Validation of an integrative model of e-filing continuance usage. Gov Inform Q. 2018;35(2):161-74.

29. Oghuma AP, Libaque-Saenz CF, Wong SF, Chang Y. An expectation-confirmation model of continuance intention to use mobile instant messaging. Telemat Inform. 2016;33(1):34-47.

30. Lee MC. Explaining and predicting users' continuance intention toward e-learning: An extension of the expectation-confirmation model. Comput Educ. 2010;54(2):506-16.

31. Bhattacherjee A, Perols J, Sanford C. Information technology continuance: A theoretic extension and empirical test. J Comput Inform Syst. 2008;49(1):17-26. 
32. Sarkar S, Khare A. Influence of expectation confirmation, network externalities, and flow on use of mobile shopping apps. Int J Hum-Comput Int. 2019;35(16):1449-1460.

33. Al-Emran M, Arpaci I, Salloum SA. An empirical examination of continuous intention to use mlearning: An integrated model. Educ Inf Technol. 2020;25(4):2899-918.

34. Liao C, Chen JL, Yen DC. Theory of planning behavior (TPB) and customer satisfaction in the continued use of e-service: An integrated model. Comput Hum Behav. 2007;23(6):2804-22.

35. Jussila I, Tarkiainen A, Sarstedt M, Hair JF. Individual psychological ownership: Concepts, evidence, and implications for research in marketing. J Market Theory Prac. 2015;23(2):121-39.

36. Al-Qerem WA, Jarab AS. COVID-19 vaccination acceptance and its associated factors among a Middle Eastern population. Front Public Health. 2021;9:34.

37. Catalano HP, Knowlden AP, Birch DA, Leeper JD, Paschal AM, Usdan SL. Using the theory of planned behavior to predict HPV vaccination intentions of college men. J Am Coll Health. 2017;65(3):197207.

38. Homer PM, Kahle LR. A structural equation test of the value-attitude-behavior hierarchy. J Pers Soc Psychol. 1988;54(4):638-46.

39. Park E. User acceptance of smart wearable devices: An expectation-confirmation model approach. Telemat Inform. 2020;47:101318.

40. Feng Y, Zong M, Yang Z, Gu W, Dong D, Qiao Z. When altruists cannot help: the influence of altruism on the mental health of university students during the COVID-19 pandemic. Globalization Health. 2020;16(1):1-8.

41. Hansstein FV, Echegaray F. Exploring motivations behind pollution-mask use in a sample of young adults in urban China. Globalization Health. 2018;14(1):1-10.

42. Chong YY, Chien WT, Cheng HY, Kassianos AP, Gloster AT, Karekla M. Can psychological flexibility and prosociality mitigate illness perceptions toward COVID-19 on mental health? A cross-sectional study among Hong Kong adults. Globalization Health. 2021;17(1):1-13.

43. Rana RH, Alam K, Gow J.Development of a richer measure of health outcomes incorporating the impacts of income inequality, ethnic diversity, and ICT development on health. Globalization Health. 2018;14(1):1-12.

44. Xue YL, Huang ZM, Liu GH, Zhang ZC, Feng YF, Xu MY, Jiang LJ, Li WY, Xu J. Associations of environment and lifestyle factors with suboptimal health status: a population-based cross-sectional study in urban China. Globalization Health. 2021;17(1):1-12.

45. Zhang L, Ma M, Li D, Xin Z. The psychological typhoon eye effect during the COVID-19 outbreak in China: the role of coping efficacy and perceived threat. Globalization Health. 2020;16(1):1-10.

\section{Figures}




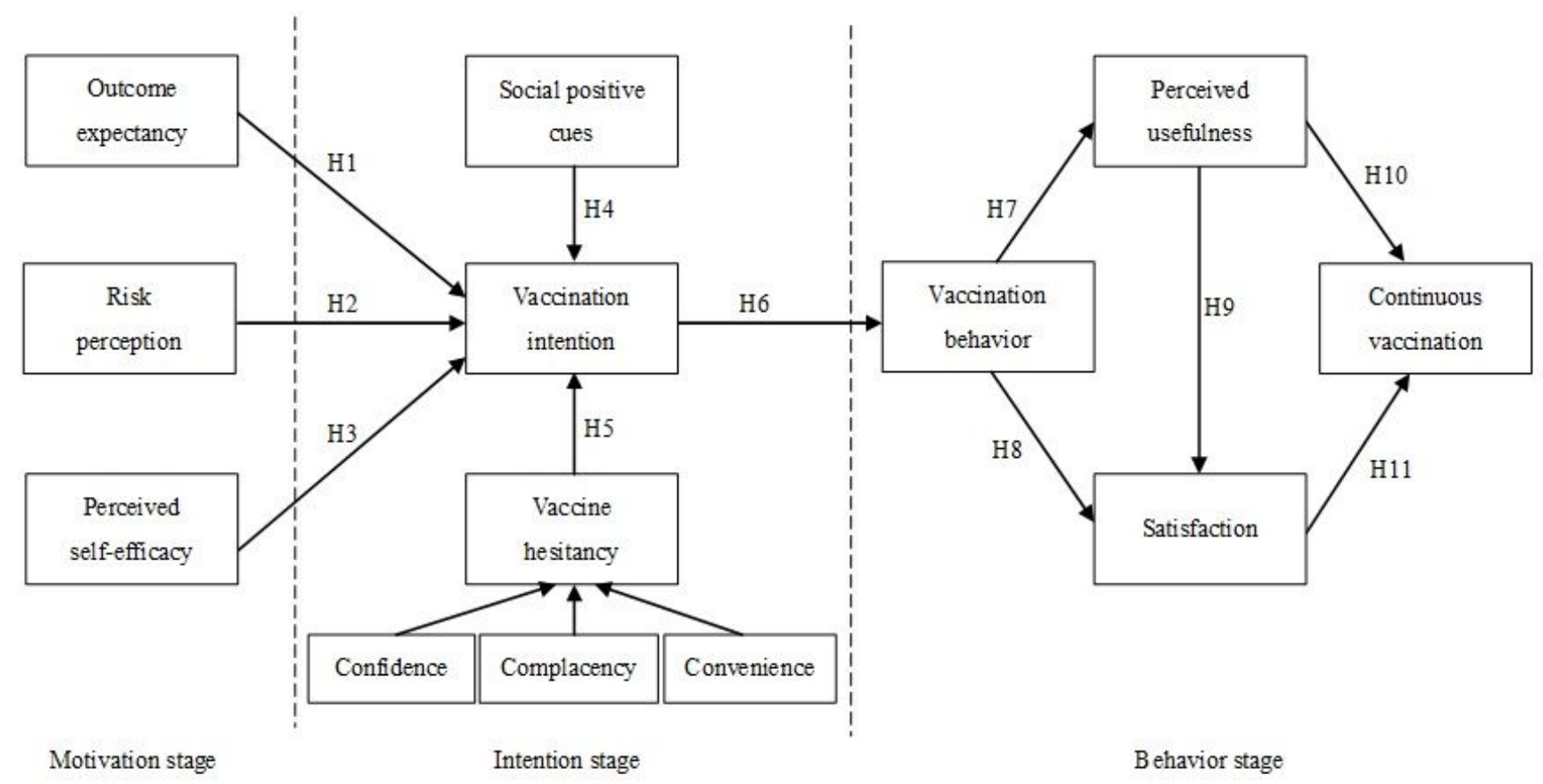

Figure 1

Research Model

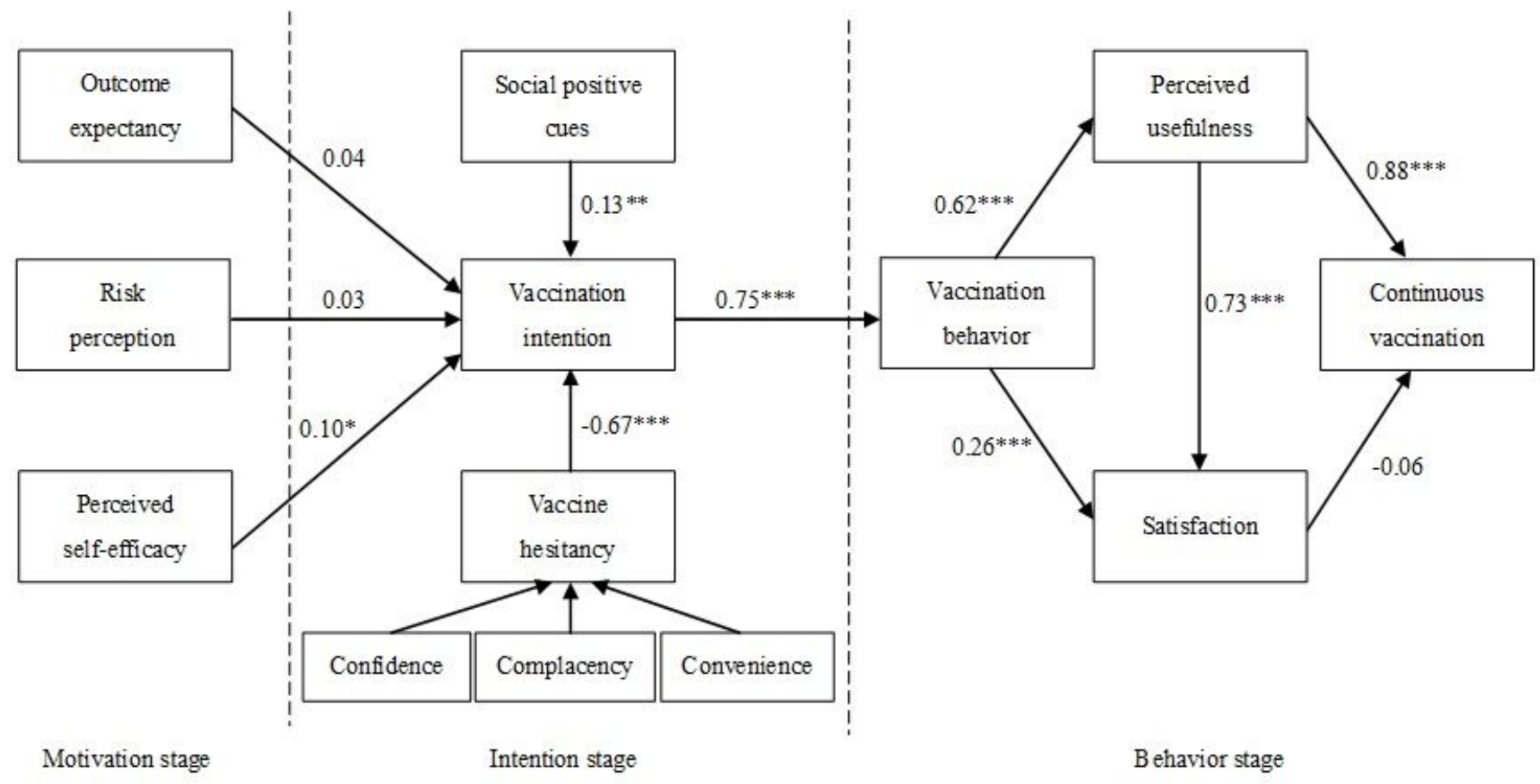

Figure 2

Hypothesis testing results. Note: ${ }^{\star} p<0.05,{ }^{* \star} p<0.01,{ }^{\star \star \star} p<0.001$. 